\title{
The Effect of Vocabulary Self -Selection Strategy and Input Enhancement Strategy on the Vocabulary Knowledge of Iranian EFL Learners
}

\author{
Golfam Masoudi ${ }^{1}$ \\ ${ }^{1}$ Department of TEFL, Faculty of Foreign Languages, Islamic Azad University North Tehran Branch, Tehran, \\ Iran \\ Correspondence: Golfam Masoudi, Department of TEFL, Faculty of Foreign Languages, Islamic Azad \\ University North Tehran Branch, Tehran, Iran
}

Received: May 22, 2017 Accepted: July 2, 2017 Online Published: July 4, 2017

doi: 10.5539/elt.v10n8p32 URL: http://doi.org/10.5539/elt.v10n8p32

\begin{abstract}
The present study was designed to investigate empirically the effect of Vocabulary Self -Selection strategy and Input Enhancement strategy on the vocabulary knowledge of Iranian EFL Learners. After taking a diagnostic pretest, both experimental groups enrolled in two classes. Learners who practiced Vocabulary Self-Selection were allowed to self-select each word from the text they wanted to, but the learners who practiced Input Enhancement strategy one session later than the other group, were just allowed to choose the words among the textually enhanced ones which were just limited to the finalized words of the Vocabulary Self-Selection group. After about three months of treatment, seen and unseen posttests were administered. The results revealed positive effects of both strategies on the vocabulary knowledge of the Iranian EFL learners. Thus it could be safely concluded that Vocabulary Self-Selection and Input Enhancement strategy were quite effective in the development of vocabulary knowledge. The performance of the two groups of Iranian EFL learners on the achievement posttest, as statistically shown, indicates that the Vocabulary Self-Selection group could outperform the Input Enhancement group on the vocabulary knowledge. The results revealed positive effects of both strategies on the vocabulary knowledge of the Iranian EFL learners. It was finally concluded that Vocabulary Self-Selection group outperformed those in Input Enhancement group. Thus it could be concluded that Iranian EFL learners who practiced Vocabulary Self-Selection strategy outperformed those who practiced Input Enhancement. Vocabulary Self-Selection strategy fostered vocabulary learning.
\end{abstract}

Keywords: vocabulary self-selection strategy, input enhancement, vocabulary knowledge, Iranian EFL learners, vocabulary learning

\section{Introduction}

Learning vocabulary takes time and effort especially for EFL learners. Improving students' vocabulary is critical if they are to develop advanced literacy levels required for success in school and beyond, in the world of higher education and the workplace (Biancarosa \& Snow, 2006; Graves \& Watts-Taffe, 2008; Lubliner \& Grisham, 2012). In order to learn vocabulary effectively, each learner takes advantage of different strategies. Oxford (1992) stated that L2 learning strategies can help learners improve their own perception, reception, storage and retrieval of language information. According to Nation (2008), the purpose of strategy training is to get the learners to become independent and autonomous in their vocabulary learning.

One of the practical strategies that may be beneficial for both teachers and students is Vocabulary Self-Selection or Self-Collection Strategy. Haggard (1986) came up with a new approach which differs significantly from traditional instruction. This strategy is based on the self-selection of words during reading. The purpose of the Vocabulary Self-Selection strategy is to motivate students to learn new words by promoting a "long-term acquisition and development of the vocabulary of academic disciplines" with the goal of integrating "new content words into students' working vocabularies" (Ruddell, 2005, p. 166). It also, promotes students' autonomy and reading as well as use of context and reference tools. Through the strategy, students are encouraged to find words and their meanings from the reading contexts. The important point regarding the strategy is guessing the meanings of the words in the classroom which helps learners extend their knowledge of 
vocabulary (Hamada \& Park, 2011; Shokouhi \& Askari, 2010).

The strategy is a practice for learners to infer meaning from the context. Laufer and Bensoussan (1982) suggested that guessing ought to be taught by asking students to focus on the context clues. Cook (2008) stated that in order to be successful in inferring meaning, the context should be rich enough to provide adequate clues for guessing. Background knowledge about the topic and culture and repeated encounters with a word in diverse contexts are important, as well. Reading, collaboration, and peer learning are the essentials of this strategy. Although reading a text is an activity that people prefer to do individually and without interruption, reading together in class can be an enjoyable task since students can help one another in the process of comprehension. Also, they can share their reactions toward the text. Most researchers believe that students learn better in collaborative groups than in traditional classroom settings. Wills (2007) referred to some of the psychosocial advantages of cooperative learning. He argued that group working reduces the fear of failure among students; they can access the stored information much easier during cooperative learning situations. This research-based strategy captures the essence of vocabulary learning as it provides students with multiple exposures to a word, multiple readings of a text, collaboration of students and teacher, oral discussions and presentations, selecting words that are important to know and sharing their ideas with their classmates. Haggard (1982) stated that the strategy is an interactive-learning instructional strategy that promotes word consciousness, as students actively engage in identifying important words in the reading passage and share their choices with other classmates. The strategy has been adopted for various grade levels and instructional contexts. The context in which the students are reading certainly fosters understanding of a word (Haggard, 1986).

One of the major benefits of using Vocabulary Self-Selection strategy is that students engage in their own learning, discover how to recognize unfamiliar words from their readings, develop their vocabulary knowledge, and become word conscious. According to Haggard (1982), Vocabulary Self-Selection is a structure that makes students independent over time. The learners have pivotal role in enhancing their autonomy in vocabulary learning as they decide which words are worth learning. Also, they learn how to use the words within a context. Teachers who manipulate this strategy, model the process of collecting words, provide guided practice within reading groups and other instructional contexts, and offer consistent encouragement to students to use Vocabulary Self-Selection strategy during independent reading. In learner autonomous world of vocabulary learning, the teacher's role is reduced as facilitators (Haggard, 1982).

One of the elements of Vocabulary Self-Selection strategy is writing down the nominated words on the board. This would be beneficial as it is highly flexible during presentation and therefore bears several advantages. Writing on the board subconsciously makes students pay attention to what is written down. This feature widens the teacher's options on how to present or review language in a meaningful way (Ruddell \& Shearer, 2002).

On the other hand, Input Enhancement or Textual Enhancement is another strategy that can enhance vocabulary learning. Students' awareness of what they are going to learn may facilitate learning. Sharwood Smith (1991) stated that while input enhancement is presumed to increase the chances that learners will attend to a target form and even if they do pay attention to the enhanced form, there is no guarantee that they will internalize the form. It was for this reason that Sharwood Smith replaced his earlier term "consciousness-raising" with "input enhancement." Using typographical cues such as bolding and italics to draw the reader's attention to particular information in a text is known as textual enhancement. Textual enhancement is used to draw language learner's attention. The input is written, the target item is then enhanced by visually altering its appearance in the text. Textual enhancement directs learners' attention to form while encouraging them to process meaning-bearing input. The aim of Textual Input Enhancement is to change the way input is perceived and processed by language learners. People learn about the things that they pay attention to and do not learn much about the things they do not attend to. According to Lightbown (2000), we should not expect learners to immediately use the target forms accurately in production even when they do notice forms.

The aim of this study was to examine whether Vocabulary Self-Selection strategy as a strategy which fosters learner autonomy could be as beneficial as Input Enhancement strategy in learning vocabulary.

To sum it up, the teacher should help students build up and use a mental lexicon in such a way that they will be capable of storing, keeping and retrieving words when needed. He or she can call on various methods to aid him or her in accomplishing this task, mainly arousing motivation and attention, engaging in meaningful activities and providing many channels for learning and practicing. This study aimed to measure the effect of Vocabulary Self-Selection strategy and Input Enhancement strategy on the vocabulary knowledge of Iranian EFL learners. 


\section{Material and Methods}

\subsection{Instrumentation}

In order to achieve the objective of the current study, the following instruments were utilized by the researcher:

1) The first instrument used in this study was a 50-item multiple-choice vocabulary test developed by the researcher. The vocabulary items were selected from among the new words of the texts which were going to be taught during the course. The dependability of the test was estimated through Kappa coefficient. The degree of dependability was $\mathrm{k}=0.80$. In order to ensure the content validity of the test, two experts were asked to review the test. The test was revised based on their suggestions. This vocabulary test was utilized as diagnostic pretest and seen achievement posttest. Having a diagnostic function, the multiple-choice pretest could determine whether the students knew the definition of the target words prior to the treatment. The purpose of the achievement seen posttest was to determine the effect of Vocabulary Self-Selection, and Input Enhancement on the vocabulary knowledge of the Iranian EFL learners. The time allocated to the test was 50 minutes.

2) The second instrument used in this study was a 20 -item multiple-choice vocabulary test developed by the researcher. This test was developed in order to control the practice effect of the seen posttest, and to increase the internal validity of the study. This test was administered one session after the seen posttest was run. The vocabulary items were selected from among the finalized words which the Vocabulary Self-Selection group had chosen throughout the treatment. The content of the unseen posttest was also reviewed by two experts. The degree of dependability was $\mathrm{k}=0.70$ for the unseen posttest. The allocated time for the test was 20 minutes.

\subsection{Materials}

Three kinds of materials were utilized in order to achieve the objective of the study.

1) Ten illustrated texts, which were chosen based on the students' interests, were given to the Vocabulary Self-Selection group. However, the texts of the Input Enhancement group were highlighted based on the selected words by the Vocabulary Self-Selection group.

2) A vocabulary graph which was drawn on the board at the beginning of each session.

Table 1. Vocabulary graph

\begin{tabular}{|l|l|}
\hline We Selected Two Words & 2nd Word:----------- \\
\hline 1st Word:-------- & The Word In The Sentence \\
The Word In The Sentence & Sentence:---------- \\
Sentence:-------- & The Meaning That We Guessed \\
The Meaning That We Guessed & Meaning:-------- \\
Meaning:------- & Dictionary Meaning \\
Dictionary Meaning & Dictionary Meaning:-------- \\
Dictionary Meaning:-------- &
\end{tabular}

3) Index-cards which were used for recording and storing new words and their definitions which were utilized by the Vocabulary Self-Selection group.

\subsection{Procedure}

The following steps were taken in order to accomplish the purpose of the study during the research process.

\subsubsection{Pretest}

The diagnostic pretest was administered to the students at the beginning of the course to determine whether the students were familiar with the words which were going to be covered during the course. The researcher asked learners to answer the vocabulary items and not to leave them unanswered even if they were not sure about the correct answer. The students' pretest was scored for analysis. 


\subsubsection{Vocabulary Self-Selection Group}

Twenty pre-intermediate Iranian EFL learners attended Vocabulary Self-Selection group. During 24 sessions (each week 2 sessions) which lasted for about three months, 10 illustrated short texts were utilized. The allocated time to the each session was about 30 minutes.

At the beginning of the course, the purpose of Vocabulary Self-Selection strategy was explained to the learners. Students were expected to select some words from their reading texts. The learners were free to select any words throughout the text that they wished. The researcher modeled how to select and choose important words from the reading texts. She selected a difficult word from the text and explained to the participants that without knowing some key words, comprehension of the texts would be impeded. Thus, she encouraged and motivated students to self-select the words which seemed to play a key role in comprehension of the passages. The researcher demonstrated how to use the contextual clues to guess the meaning of the unknown words. Finally, she wrote down the selected words on the vocabulary graph which was drawn on the board.

The students were organized randomly in groups. The group members never changed till the end of the course. Each group which consisted of four learners chose a name for itself. The groups were provided with the same text. Learners went through the texts and started finding the words they believed that should be learnt. Within their groups, the students talked about each word and used context clues to guess their meanings. The entire group shared their ideas about the vocabularies they had selected. The group discussions lasted for 15 minutes in each session. Group discussion allowed other students to add information as students' related meanings both to personal experience and text events.

Each group were expected to self-select five words and agreed upon the finalized words. The similar words among the groups were deleted by the help of the researcher under her indirect supervision. Each group presented two words to the class. One member of each group came to the board and wrote down their chosen words on the vocabulary graph. The learner wrote the word, the sentence in which the word was used, and the meaning which they had guessed. The researcher and students negotiated the meaning of the vocabularies. Finally, the proper and even simplified dictionary meaning was written by the help of the researcher. Each group wrote down its selected vocabularies on the board. At the end of each session, students were asked to copy the finalized words on the index cards which they had provided and wrote the definition and the sentence on the lined side of the card.

Follow up activity was also conducted to help students master and retain meaning of the new words. The activity was a sort of card game which was played every three sessions. During the game, each group laid their vocabulary cards out on its desktop with only the words showing. The researcher then called out the definition and the groups selected and hold up the related vocabulary card.

What exactly students did in the class in one of the sessions is signified in Table2.

Table 2. Steps duringthe treatment sessions (vocabulary self-selection group)

\begin{tabular}{ll}
\hline Steps & Activity \\
\hline 1 & The students were organized randomly in groups. \\
2 & The groups were provided with a same text. \\
Steps & Activity \\
3 & Learners went through the texts and self-selected the words they believed that should be learnt. \\
4 & Students talked about each word, the meaning which they guessed through the text. \\
5 & Each group selected and presented two words to the class. \\
6 & $\begin{array}{l}\text { One member of each group came to the board and wrote the selected vocabulary, the sentence and the } \\
\text { meaning which was guessed on the vocabulary graph. }\end{array}$ \\
7 & $\begin{array}{l}\text { Researcher helped students to simplify and write down the proper dictionary meaning. } \\
8\end{array}$ \\
9 & $\begin{array}{l}\text { Students were asked to write the words on their index cards. } \\
\text { new words. }\end{array}$ \\
\hline
\end{tabular}




\subsubsection{Input Enhancement Group}

Twenty pre-intermediate Iranian EFL learners attended Input Enhancement group. The course of this group started one session later than the Vocabulary Self Selection group. The reason behind this timing was that the researcher needed some time to highlight the selected words by the Vocabulary Self Selectiongroup in the texts.

During 24 sessions (each week 2 sessions) which lasted for about three months, 10 illustrated texts were utilized. It should be mentioned that Input Enhancement group was provided with the same texts but the only difference wasthat the selected words were highlighted in the text. The time allocated to the treatment in each session was about 30 minutes.

At the beginning of the course, the purpose of strategy was explained to the learners. Students were allowed to select the new words from among the textually enhanced vocabularies. The researcher modeled how to select and choose the highlighted words from the reading texts. Learners were randomly organized in groups of four. Each group chose a name for itself. The groups were provided with the enhanced texts, prepared by the researcher, and started finding the enhanced words that they thought they had to learn.

It is worth mentioning that the students had to select the words only from among the words which were textually enhanced. Within their groups, the students talked about the meaning of the chosen words using the context provided in the reading passages. The group discussions lasted for 15 minutes in each session.

Each group was expected to select five words. The similar words among the groups were deleted by the help of the teacher under her indirect supervision. Each group presented two textually enhanced words to the class. A member from each group came to the board and wrote down their word choices on the vocabulary graph. She wrote the word, the sentence in which the word was used, and the meaning which the group had guessed. After discussion on the definition of the words in the class, the appropriate dictionary meaning was written by the help of the researcher. At the end of each session students were asked to write down the words in their note books. What exactly students did in the class in one of the sessions is signified in Table 3.

Table 3. Steps duringthe treatment sessions (input enhancement group)

\begin{tabular}{ll}
\hline Steps & Activity \\
\hline 1 & The students were organized randomly in groups. \\
2 & The groups were provided with a same text. \\
3 & Learners went through the texts and selected the words they believed that should be learnt. \\
4 & Students talked about each word, the meaning which they guessed through the text. \\
5 & Each group selected and presented two highlighted words to the class. \\
6 & $\begin{array}{l}\text { One member of each group came to the board and wrote the selected vocabulary on the vocabulary } \\
\text { graph. }\end{array}$ \\
8 & Researcher helped students to simplify and write down the proper dictionary meaning. \\
\end{tabular}

\subsubsection{Posttest}

The achievement seen posttest was administered to the students at the end of the course (week 12). The scores were processed by using the same procedures as the pretest. The scores were used to determine the changes and development in the vocabulary knowledge of the Iranian EFL learners. The allocated time to the posttest was 50 minutes. The unseen posttest was also run one session after the seen posttest. The time allocated to the unseen posttest was 20 minutes.

\section{Results}

\subsection{Input Enhancement Group}

Prior to the course, Input Enhancement group participated in diagnostic pretest. Among 20 learners, the average of $33 \%$ answered the questions correctly. All of the students performed as non-masters as they fell below $60 \%$ cut-point and the B-index mean was -0.33 that indicates learners needed to learn the material. Table 4 shows the pretest results in detail. 
Table 4. Descriptive statistics, vocabulary pretest

\begin{tabular}{lllllll}
\hline Variable & $\mathrm{N}$ & $\mathrm{M}$ & $\mathrm{SD}$ & Variance & Skewness & $\begin{array}{l}\text { Std. Error of } \\
\text { Skewness }\end{array}$ \\
\hline $\begin{array}{l}\text { Input Enhancement } \\
\text { Group Pretest }\end{array}$ & 20 & 16.5000 & 4.82864 & 23.316 & .946 & .512 \\
\hline
\end{tabular}

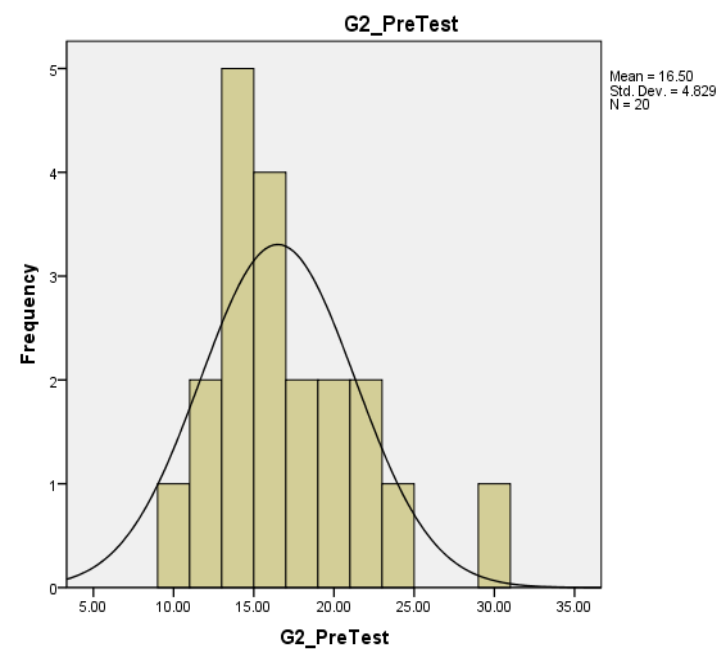

Figure 1. Distribution of pretest scores

After treatment which lasted three months, seen posttest was administered. The average of $68 \%$ Input Enhancement group who was exposed to Input Enhancement strategy answered the questions correctly. Only two students fell below the cut-point. The B-index was 0.13. The details are shown in Table 5. Figure 2 indicates the distribution of scores and the skewness ratio of the seen posttest is 0.284 .

Table 5. Descriptive statistics, vocabulary posttest

\begin{tabular}{lllllll}
\hline Variable & $\mathrm{N}$ & $\mathrm{M}$ & $\mathrm{SD}$ & Variance & Skewness & $\begin{array}{l}\text { Std. Error of } \\
\text { Skewness }\end{array}$ \\
\hline $\begin{array}{l}\text { Input Enhancement } \\
\text { Group Posttest }\end{array}$ & 20 & 33.8000 & 3.05390 & 9.326 & .284 & .512 \\
\hline
\end{tabular}

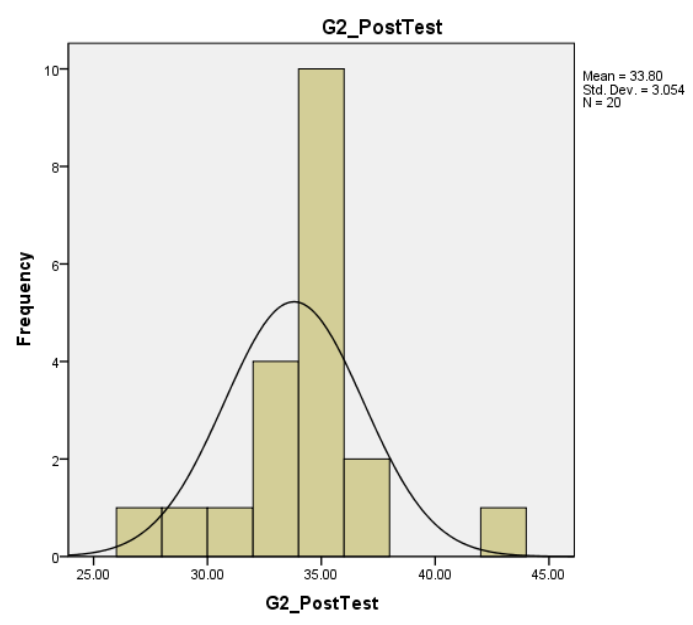

Figure 2. Distribution of posttest scores 
But regarding the second posttest the average of $69 \%$ answered the questions correctly and the B-index of 0.16 . Table 6 shows results in detail. The distribution of scores is shown in Figure 3.

Table 6. Descriptive statistics, vocabulary unseen posttest

\begin{tabular}{lllllll}
\hline Variable & $\mathrm{N}$ & $\mathrm{M}$ & $\mathrm{SD}$ & Variance & Skewness & $\begin{array}{l}\text { Std. Error of } \\
\text { Skewness }\end{array}$ \\
\hline $\begin{array}{l}\text { Input Enhancement } \\
\text { Group Unseen Posttest }\end{array}$ & 20 & 13.7000 & 1.62546 & 2.642 & -.194 & .512 \\
\hline
\end{tabular}

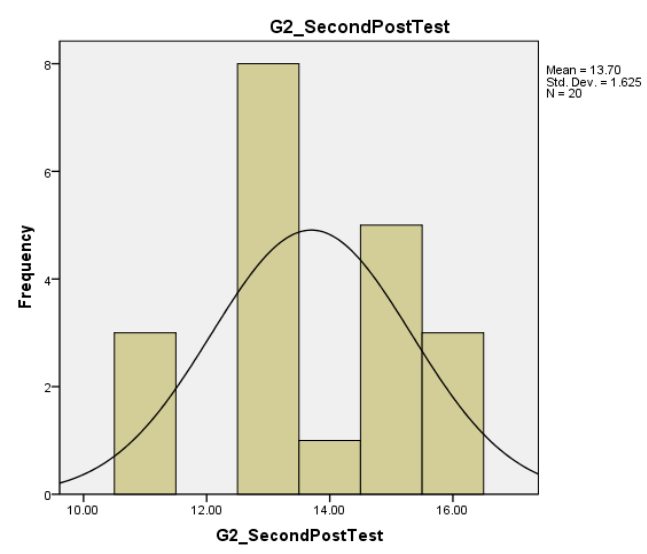

Figure 3. Distribution of unseen posttest scores

The comparison of the means on the pretest and posttest scores of Input Enhancement group indicated that there was a statistically difference $(t=33.03, d f=19, p=0.000>0.05)$ between the performance of Input Enhancement group in pretest and achievement posttest as its shown in Table 7. It could be safely concluded that the Input Enhancement strategy was effective in improving vocabulary knowledge of Iranian EFL learners.

Table 7. T-Test for Vocabulary Pretest \& Posttest (Input Enhancement group)

\begin{tabular}{|c|c|c|c|c|c|c|c|c|}
\hline & \multicolumn{8}{|c|}{ Paired Differences } \\
\hline & \multirow[b]{2}{*}{ Mean } & \multirow{2}{*}{$\begin{array}{l}\text { Std. } \\
\text { Deviation }\end{array}$} & \multirow{2}{*}{$\begin{array}{l}\text { Std. Error } \\
\text { Mean }\end{array}$} & $\begin{array}{l}95 \% \\
\text { Interval }\end{array}$ & Confidence & \multirow[t]{2}{*}{$\mathrm{t}$} & \multirow[t]{2}{*}{$\mathrm{df}$} & \multirow{2}{*}{$\begin{array}{l}\text { Sig. } \\
\text { (2-tailed) }\end{array}$} \\
\hline & & & & Lower & Upper & & & \\
\hline Input & & & & & & & & \\
\hline $\begin{array}{l}\text { Enhancement } \\
\text { Group Pretest } \\
\text { and Posttest }\end{array}$ & 34.60000 & 4.68368 & 1.04730 & 32.40797 & 36.79203 & 33.037 & 19 & .000 \\
\hline
\end{tabular}

This study aimed at accepting or rejecting the null hypothesis, thus the independent $t$-test was run to compare the means of the two experimental groups.

$\mathrm{H}_{0}$ : There is no significant difference between the vocabulary knowledge of those Iranian EFL learners who practice Self-Selection strategy and those who are exposed to Input Enhancement strategy.

As Table 8 indicates, Levene's test shows the significance of 0.369 which is higher than 0.05 so the condition of homogeneity of the variances was met. The results of the independent $t$-test $(t=12.56, d f=38, p=0.000>0.05)$ indicated that there was statistically significance between the learners who were exposed to Vocabulary Self-Selection strategy and Input Enhancement strategy. It is safely concluded the null hypothesis is rejected and there is significant difference between the vocabulary knowledge of those Iranian EFL learners who practiced through Self-Selection strategy and those who were exposed to Input Enhancement strategy. Considering that the 
mean of Vocabulary Self-Selection strategy is higher than the mean of Input Enhancement strategy, thus the EFL learners who were exposed to Vocabulary Self-Selection strategy performed quite better than the EFL learners who were exposed to Input Enhancement strategy.

Table 8. Independent samples test

\begin{tabular}{|c|c|c|c|c|c|c|c|c|c|}
\hline & $\begin{array}{l}\text { Leve } \\
\text { Test } \\
\text { Equa } \\
\text { Varia }\end{array}$ & $\begin{array}{l}\text { for } \\
y \text { of } \\
\text { ces }\end{array}$ & t-test fo & Equality & of Means & & & & \\
\hline & $\mathrm{F}$ & Sig. & $\mathrm{t}$ & $\mathrm{df}$ & $\begin{array}{l}\text { Sig. } \\
\text { (2-tailed) }\end{array}$ & $\begin{array}{l}\text { Mean } \\
\text { Difference }\end{array}$ & $\begin{array}{l}\text { Std. Error } \\
\text { Difference }\end{array}$ & $\begin{array}{l}95 \% \\
\text { Interval } \\
\text { Difference }\end{array}$ & $\begin{array}{l}\text { Confidence } \\
\text { of the }\end{array}$ \\
\hline & & & & & & & & Lower & Upper \\
\hline $\begin{array}{l}\text { Equal } \\
\text { variances } \\
\text { assumed }\end{array}$ & .826 & .369 & 12.567 & 38 & .000 & 20.90000 & 1.66307 & 17.53330 & 24.26670 \\
\hline $\begin{array}{l}\text { Equal } \\
\text { variances } \\
\text { not assumed }\end{array}$ & & & 12.567 & 35.183 & .000 & 20.90000 & 1.66307 & 17.52442 & 24.27558 \\
\hline
\end{tabular}

As Table 9 indicates, there is a statistically significant difference $(\mathrm{t}=11.56, \mathrm{df}=38, \mathrm{p}=0.000>0.05)$ between the mean of the unseen posttest of the learners who were exposed to Vocabulary Self-Selection strategy and the Iranian EFL learners who practiced Input Enhancement strategy. It is concluded that there is a significant difference between the unseen posttest of the Vocabulary Self-Selection and the Input Enhancement groups. Considering that the mean of Vocabulary Self-Selection group is higher than Input Enhancement group, the Vocabulary-Self Selection was more effective in vocabulary knowledge than Input Enhancement strategy.

Table 9. Independent samples test of the unseen posttest

\begin{tabular}{|c|c|c|c|c|c|c|c|c|c|}
\hline & $\begin{array}{l}\text { Levene } \\
\text { Test } \\
\text { Equalit } \\
\text { Variano }\end{array}$ & $\begin{array}{l}\text { for } \\
\text { f of } \\
\text { es }\end{array}$ & $\mathrm{t}$-test fo & Equality & of Means & & & & \\
\hline & $\mathrm{F}$ & Sig. & $\mathrm{t}$ & $\mathrm{df}$ & $\begin{array}{l}\text { Sig. } \\
\text { (2-tailed) }\end{array}$ & $\begin{array}{l}\text { Mean } \\
\text { Difference }\end{array}$ & $\begin{array}{l}\text { Std. Error } \\
\text { Difference }\end{array}$ & $\begin{array}{l}95 \% \\
\text { Interval } \\
\text { Difference }\end{array}$ & $\begin{array}{l}\text { Confidence } \\
\text { of the }\end{array}$ \\
\hline & & & & & & & & Lower & Upper \\
\hline $\begin{array}{l}\text { Equal } \\
\text { variances } \\
\text { assumed }\end{array}$ & 3.104 & .086 & 11.561 & 38 & .000 & 23.75000 & 2.05436 & 19.59117 & 27.90883 \\
\hline $\begin{array}{l}\text { Equal } \\
\text { variances } \\
\text { not assumed }\end{array}$ & & & 11.561 & 35.155 & .000 & 23.75000 & 2.05436 & 19.58008 & 27.91992 \\
\hline
\end{tabular}

Finally Figure 4 indicates the performance comparison of students who were exposed to Vocabulary Self-Selection strategy and the students who practiced Input Enhancement strategy throughout the course. 


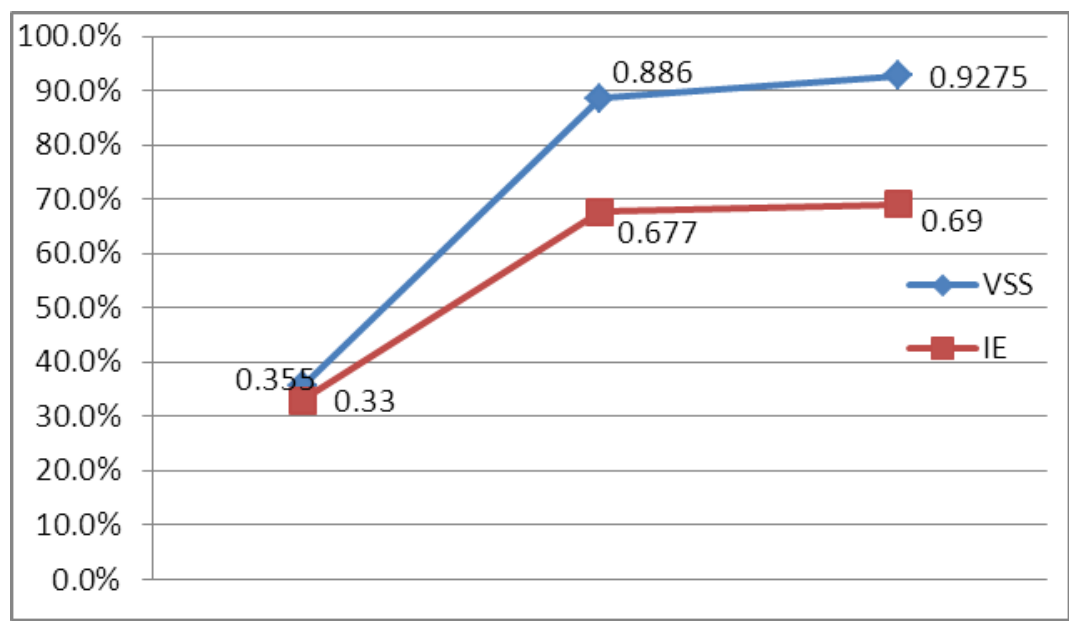

Figure 4. Comparison of vocabulary self selection and input enhancement group

\section{Discussion}

Input enhancement is one of the popular implicit techniques used in focus on form instruction which draws the attention of learners to input without specific explanation from teachers. The input enhancement technique can be adapted easily to vocabulary learning. The study shows the effectiveness of textual enhancement on the vocabulary knowledge of the learners and the results are in line with Fahim and Vaezi (2011) who claimed that Input enhancement is quite effective in learning vocabulary. Hwang (2004) also found that visual input enhancement of vocabulary partly had an effect on word recognition. Some vocabulary which was visually enhanced increased learners' intake in their working memory although there were no effects on long-term retention. He also stated that visual input enhancement helped learners' noticing, but it did not boost the rate of unknown vocabulary acquisition in the reading process. The result of this study showed the performance of learners who practiced Input Enhancement was not quite satisfactory on the achievement posttest.

In comparison, Vocabulary Self-Selection is totally a different strategy. According to Haggard (1986) this strategy is designed to encourage students to expand their vocabulary knowledge. Haggard (1988) stated that Vocabulary Self-Selection strategy incorporates a feature which differs from traditional instruction by using student-generated as opposed to preselected word lists.

During the treatment, Vocabulary Self -Selection group performed more motivated in guessing the unknown words in comparison to Input Enhancement group. Considering that Input Enhancement group were not allowed to choose any words that they wanted to, they didn't feel confident and independent as they were just encountered with some enhanced vocabularies which were not necessarily enough for comprehending the text.

Vocabulary Self-Selection strategy differs significantly from other approaches, however, by its emphasis on student choice in deciding what words are to be studied and students experience as the basis for determining word meaning. According to Haggard (1985), Vocabulary Self-Selection strategy is an effective instructional alternative as it stimulates interest and enthusiasm, builds upon and expands word knowledge and establishes independent learning behaviors.

Vocabulary Self-Selection strategy focuses on the words that the students want and need to know as it lead students toward independency. The result of the present study is in line with Harmon and Hedrick (2005) who claimed that struggling readers learn vocabulary when teachers "encourage independent learning by allowing students to self-select terms to be studied" (p. 275). They also stated that the sense of autonomy and independency played a prominent role in developing vocabulary knowledge. Benson (2003) stated that students who think and work strategically are more motivated to learn and have a higher sense of self-efficacy or confidence in their own learning ability. According to Boud (1995), autonomous learners in learning vocabulary have a continuous desire for learning vocabulary and develop their strategic ways of learning. This study showed that the sense of autonomy and independency of those learners who were exposed to Self-Selection strategy caused them to perform quite better than the learners who practiced Input Enhancement strategy.

\section{Conclusion}

This study aimed to examine whether taking advantage of Vocabulary Self-Selection and Input Enhancement 
could enhance learners' vocabulary knowledge.

The participants of this study were 40 pre-intermediate Iranian girls aged between 14 and 16 years in two classes. The treatment began in February 2014 and ended in April 2014. All through the course, both experimental groups were provided with the same illustrated short texts and benefited from team work and collaboration. The students who practiced Vocabulary Self-Selection strategy were allowed to choose each unknown vocabulary they encountered through the text. Every three sessions, the researcher reminded the words the students had covered by playing with index cards. On the other hand, the learners who were exposed to Input Enhancement strategy were expected to choose the words from among the enhanced and textually highlighted ones. They were not provided with any index cards and actually no games. The first and last sessions of the course were allocated to the pretest and posttest. The unseen posttest was administered one session after the administration of the seen posttest to increase the internal validity of the study.

The development of the vocabulary knowledge of each experimental group was assessed by comparing the pretest, seen posttest and also the unseen posttest scores. In order to determine the statistically significant difference between the performances of the learners who practiced Vocabulary Self-Selection strategy and those who practiced Input Enhancement, two t-tests were run. After the data analysis, the researcher attempted to answer the following research question and null hypothesis:

RQ: What is the effect of Vocabulary Self-Selection strategy versus Input Enhancement strategy on the vocabulary knowledge of Iranian EFL learners?

$\mathrm{H}_{0}$ : There is no significant difference between the vocabulary knowledge of those Iranian EFL learners who practice Self-Selection strategy and those who are exposed to Input Enhancement strategy.

The statistical analysis indicated that the learners' vocabulary knowledge had improved during the course as the result of the treatment they received. The sense of participation and having control over their learning motivated the learners. The results show the Vocabulary Self-Selection group outperformed Input Enhancement group in the posttest and learners who practiced Vocabulary Self-Selection benefited more from the strategy. It could be safely concluded that Vocabulary Self-Selection strategy is more effective than Input Enhancement as it stimulates interest and enthusiasm and establishes independent learning behaviors. In spite of the results which are obtained, the role of Input enhancement in word knowledge couldn't be neglected or rejected at all.

\subsection{Pedagogical Implications}

This study has a number of implications for Iranian EFL learners, teachers, and classroom settings:

1) Based on the findings, improving vocabulary knowledge through the interesting reading texts is considered as an effective strategy which could be beneficial for both teachers and learners. The illustrated reading texts cause students to read the texts more eagerly.

2) Teamwork and collaboration motivate students to participate in groups, express their ideas, and negotiate with their peers. The more the learners engage in teamwork, the more confident they feel. Most researchers believe that students learn better in collaborative groups than in traditional classroom settings.

3) This study aimed to foster autonomy. The findings of the study showed that learners who participate in student-centered classes find the learning process more meaningful as they actively engage in learning. According to Cannon (2000), learning is promoted in the learning environments which have learner responsibility and activity at their heart. Teachers can benefit from the strategies which assist them in developing student-centered classrooms. Allowing students to self-select words is a powerful vocabulary teaching tool that builds autonomy.

4) Using Vocabulary Self-Selection strategy could facilitate vocabulary learning since it provided an association between words and their meanings.

5) Taking advantage of follow up activities such as index card games is considered as a useful tool which may be beneficial in the English language learning classes and can make the lessons more interesting and enjoyable. As Decarrico (2001) pointed out, words should not be learnt separately or by memorization without understanding.

\section{References}

Benson, P. (2003). Learner autonomy in the classroom. In D. Nunan (Ed.), Practical English language teaching (pp. 289-308).Higher education press: McGraw Hill. https://doi.org/10.1057/9780230504684_2

Biancarosa, C., \& Snow, C. E. (2006). A vision for action and research in middle and high school literacy: A report to Carnegie Corporation of New York. Washington, DC: Alliance for Excellent Education. 
Boud, D. (1995). Moving towards autonomy in developing student autonomy in learning. NY: Nicholas Publishing.

Cook, V. (2008). Second language learning and language teaching. London: Edward Arnold.

Decarrico, J. S. (2001). Vocabulary learning and teaching. In M. Celce-Murcia (Ed.), Teaching English as a second or foreign language (pp. 285-300). Heinle \& Heinle: Boston.

Fahim, M., \& Vaezi, R. (2011). Investigating the effect of visually-enhanced input on the acquisition of lexical collocations by Iranian intermediate EFL learners: A case of verb-noun lexical collocations. Journal of Language Teaching and Research, 2(3), 552-560. https://doi.org/10.4304/j1tr.2.3.552-560

Graves, M. F. (2006). The vocabulary book: Learning and instruction. Newark, DE: International Reading.

Haggard, M. R. (1986). The vocabulary self-collection strategy: Using student interest and word knowledge to enhance vocabulary growth. Journal of Reading, 29(1), 634-642.

Hamada, M., \& Park, C. (2011). Word-meaning inference: A longitudinal investigation of inference accuracy and strategy use. Asian EFL Journal, 13(4), 10-32.

Harmon, J. (2008). Instructional strategies for teaching content vocabulary: Grades 4-12. Westerville, OH: National Middle School Association.

Hwang, S. (2004). The effects of input enhancement of English vocabulary and the linguistic structure (Unpublished doctoral dissertation). Chung-Anguniversity, Seoul.

Laufer, B. (1998). The development of passive and active vocabulary in a second language: Same or different? Applied Linguistics, 19(2), 255-271. https://doi.org/10.1093/applin/19.2.255

Lightbown, P. (2000). Classroom SLA research and second language teaching. Applied Linguistics, 21(4), 431-462. https://doi.org/10.1093/applin/21.4.431

Lubliner, S., \& Grisham, D. L. (2012). Cognate Strategy Instruction: Providing Powerful Literacy Tools to Spanish-Speaking Students. In J. Fingon, \& S. Ulanov (Eds.), Learning from culturally and linguistically diverse classrooms: Promoting success for all students (pp. 105-123). NY: Teachers College Press.

Nation, I. S. P. (2008). Teaching vocabulary: Strategies and techniques. Boston: Heinle.

Oxford, R. (1992). Language learning strategies in a nutshell: Update and ESL suggestion. TESOL Journal, 2(2), $18-22$.

Ruddell, M. R. (2005). Teaching content reading and writing. Hoboken, NJ: Wiley.

Ruddell, M. R., \& Shearer, B. A. (2002). Extraordinary, tremendous, exhilarating, magnificent: Middle school at risk students became avid word learners with vocabulary self-collection strategy (VSS). Journal of Adolescent \& Adult Literacy, 45(5), 352-363.

Sharwood Smith, M. (1991). Speaking to many minds: On the relevance of different types of language information for the L2 learner. Second Language Research, 7(2), 118-132. https://doi.org/10.1177/026765839100700204

Shokouhi, H., \& Askari, H. (2010). The effect of guessing vocabulary in reading authentic texts among pre-university students. Arizona Working Papers in SLA \& Teaching, 17(3), 75-89.

Wills, J. (2007). Cooperative learning is a brain turn-on. Middle School Journal, 38(4), 4-13.

\section{Copyrights}

Copyright for this article is retained by the author(s), with first publication rights granted to the journal.

This is an open-access article distributed under the terms and conditions of the Creative Commons Attribution license (http://creativecommons.org/licenses/by/4.0/). 